\title{
Trajetórias de egressos de um Programa de Orientação Profissional: contextos e escolhas
}

\author{
Tatiane Rose Oliveira de Mendonçal \\ Larissa Medeiros Marinho dos Santos \\ Universidade Federal de São João del-Rei, São João del-Rei, Minas Gerais, Brasil
}

\section{Resumo}

Da escolha de uma profissão à sua efetivação há um longo caminho a percorrer. Visando compreender como se dá esse percurso, analisou-se as trajetórias educacionais e profissionais de cinco egressos de um programa de Orientação Profissional, enfocando a relação dialética entre os elementos do contexto e as escolhas e ações dos próprios sujeitos. O trabalho foi metodologicamente guiado pela Epistemologia Qualitativa de González Rey. Para a produção de dados utilizou-se análise documental, entrevistas abertas e genoprofissiograma. Como resultado identificou-se zonas de sentido relacionadas a: influências dos pares e da família; família como base do desenvolvimento profissional; obstáculos relativos à condições socioeconômicas e saúde; estratégias para acesso a cursos e melhor colocação profissional; oportunidades; formação e atuação profissional; projetos de futuro.

Palavras-chave: orientação vocacional; escolha profissional; pesquisa qualitativa.

\section{Abstract: Trajectories of former Professional Orientation Programs' participants: contexts and choices}

From choosing a profession to its effectiveness, there is a long path to go. Aiming to understand how this path is taken, we analyzed the educational and professional trajectories of five graduates from a Professional Orientation program, focusing on the dialectical relationship between context elements and subjects' choices and actions. The research was methodologically guided by the Qualitative Epistemology of González Rey. Documentary analysis, open interviews and geno-job-profile diagram were used for data production. As a result, we identified areas of meaning related to: peer and family influences; family as the basis of professional development; obstacles to socio-economic and health conditions; strategies for access to courses and better job placement; opportunities; training and professional performance; future projects.

Keywords: vocational guidance; professional choice; qualitative research.

Resumen: Trayectorias de ex-participantes de un Programa de Orientación Profesional: contextos y elecciones Desde la elección de una profesión hasta su concretización hay un largo camino por recorrer. Con el objetivo de entender cómo se configura este recorrido, se analizaron las trayectorias educativas y profesionales de cinco ex-participantes de un programa de orientación profesional, puntualizando la relación dialéctica entre el contexto y las elecciones y acciones de los sujetos. Metodológicamente, el trabajo estuvo basado en la Epistemología Cualitativa de González Rey. Para la producción de los datos se realizaron análisis de documentos, entrevistas abiertas y genoprofesiograma. Como resultado, se identificaron zonas de sentido relacionadas con las influencias de los pares y de la familia, familia sobre la base del desarrollo profesional; obstáculos relacionados conlas condiciones socioeconómicas y de salud; estrategias para el acceso a las carreras y mejor ubicación profesional; formación y actuación profesional; proyectos futuros.

Palabras clave: orientación vocacional; elección profesional; investigación cualitativa.

1 Endereço para correspondência: Avenida Arouca, 660, sala 1007, Centro, Passos, Minas Gerais, Brasil. CEP: $37900-152$

Telefone: (35) 99707-9411. E-mail: tatianerose@yahoo.com.br 


\section{Introdução}

Uma trajetória profissional é permeada por escolhas. Mesmo após ter-se decidido por uma profissão, muitas outras situações de escolha ocorrerão no percurso profissional. A pergunta "o que vou fazer da minha vida?" já não pode ser vista como um problema apenas da adolescência, mas sim, como uma demanda que se coloca para todos no mundo do trabalho atual (Savickas et al., 2009).

Além de constante, a construção do percurso profissional é dinâmica e se configura a partir de diversos elementos individuais e contextuais. Savickas et al. (2009) afirmam que no século XXI, torna-se essencial, que as pesquisas sobre construção de carreira se atentem para esse fato e investiguem a inter-relação entre agência pessoal e estrutura social, buscando construir modelos de entendimento desse fenômeno que sejam contextualizados e, portanto, mais condizentes com a realidade atual.

Toda escolha profissional é permeada por diversos elementos, tais como oportunidades existentes, questões sociais e econômicas, localidade dos sujeitos que escolhem, dentre outros, de modo que se trata, sempre, de escolhas possíveis (Dias \& Soares, 2012). Segundo Bohoslavsky (1987), a escolha é sobredeterminada, fator relacionado à estrutura psíquica, e multideterminada, pois depende da estrutura socioeconômica. Ferretti (1988), Melo-Silva, Lassance e Soares (2004) apontam que a escolha da profissão se difere quanto ao grau de liberdade, especialmente tratando-se de profissões que exigem maior investimento em formação.Como também indica Duarte et al. (2010, p. 394):

o comportamento humano não é apenas função da pessoa, mas também do contexto. Não importa o quão estáveis podem ser as características humanas, o contexto muda rapidamente. Portanto, são necessários modelos teóricos que enfatizem a flexibilidade humana, a adaptabilidade e a aprendizagem ao longo da vida.

Dessa perspectiva é essencial na análise da escolha e sua efetivação, ponderar o contexto em que ela ocorre, o que a influencia e, muitas vezes, a determina. Deste modo, o indivíduo pode estar sujeito a diferentes condicionantes e determinantes em seu percurso, que incidindo sobre suas escolhas, colocam-no frente a dilemas para os quais precisará elaborar estratégias de enfrentamento. Por estratégia, toma-se a conceituação elaborada por Bohoslavsky (1987, p. 34), que apresentou a seguinte definição:

se refere às ações planejadas ou previstas, tendentes a atuar sobre uma situação, com a finalidade de modificá-la segundo determinados propósitos. Neste sentido, toda estratégia tem uma caráter intencional consciente, ou seja, quem a emprega sabe porque e para que a utiliza.
Quando se fala em trajetória profissional, vê-se muitas vezes esse tema atrelado a algum conceito de carreira, seja em suas concepções clássicas ou modernas (divisão proposta por Chanlat, 1995). Muitos estudos atualmente têm tomado como referência concepções como a Carreira Sem Fronteiras (Arthur, 1994; Arthur \& Rousseau, 1996) e Carreira Proteana (Hall, 1976; 2004). Bendassolli (2009) descreve outros seis modelos de carreiras emergentes além dos já citados, sendo estas: Craft Career, Carreira Portfólio, Carreira Multidirecional, Carreira Transicional, Carreira Narrativa e Carreira Construcionista. Ribeiro (2009) propõe a Carreira Psicossocial.

Savickas (2012) aponta os novos construtos de carreira como resultantes dos arranjos de trabalho atuais, em que há uma mudança nos moldes das relações de trabalho e nos atributos desejáveis pelo mercado, com a consequente exigência de adaptação por parte do trabalhador. Esse precisa ser adaptável, ter maior autoconhecimento, autoconfiança e despender mais trabalho na construção de sua identidade profissional.

Neste novo contexto, a adaptabilidade de carreira surge como um importante elemento nas trajetórias profissionais. Esta pode ser compreendida como um conjunto de características necessárias para lidar com as mudanças nas condições de trabalho e na própria vida profissional (Ambiel, 2014; Duarte, Silva, \& Paixão, 2017; Fiorini, Bardagi, \& Silva, 2016; Savickas, 2013). Para Savickas (2013, p. 153, tradução nossa) “a adaptabilidade enfatiza os processos de enfrentamento através dos quais os indivíduos se conectam às suas comunidades e constroem suas carreiras. De forma sucinta, a adaptabilidade na carreira lida com o modo como um indivíduo constrói uma carreira".

$\mathrm{Na}$ dinamicidade e instabilidade do mundo do trabalho atual, compreender o movimento de cada sujeito na construção de sua vida profissional a partir de uma única concepção de carreira pode ser limitador. Assim, Duarte et al. (2010, p. 394) afirmam que "mais do que conceber carreiras como metanarrativas de estágios, as teorias do século XXI devem abordar a carreira como se tratando de um roteiro individual." Para Duarte (2013, p. 158), carreira deve ser tomada então, "como a história de vida de cada um", visto que em cada vez menos profissões resiste a estrutura de carreira "tradicional", caracterizada por promoções sucessivas. Duarte et al. (2010) propõem o uso do termo trajetórias de vida, enfatizando o papel dos indivíduos na projeção e construção de suas vidas e seus percursos profissionais.

Consonante a esse posicionamento, neste estudo utiliza-se os termos percurso e trajetória em detrimento do termo carreira, para designar o caminho percorrido pelos participantes ao longo do tempo, interessando a dimensão formativa e profissional. Apoiou-se, ainda, na acepção de Certeau (1994), vista também em Ribeiro (2009) que apresenta trajetória como o "movimento temporal no 
espaço, isto é, a unidade de uma sucessão diacrônica de pontos percorridos, e não a figura que esses pontos formam num lugar supostamente sincrônico ou acrônico" (Certeau, 1994, p. 98, grifos do autor).

A partir do exposto, tem-se o objetivo de elucidar como participantes de um Programa de Orientação Profissional empreenderam suas trajetórias, identificando e analisando como se articularam elementos do contexto de vida desses sujeitos em relação às suas escolhas e estratégias de ação, intentando, assim, compreender a complexa trama que constitui a construção de uma carreira nos moldes atuais. Tal estudo se faz relevante ao acompanhar, através da narrativa, o processo de construção de carreira empreendida por indivíduos por cerca de 10 anos, considerando elementos contextuais relevantes e identificando, ao mesmo tempo, a participação dos sujeitos em suas escolhas e ações, descrevendo como estas podem ocorrer através estratégias de enfrentamento. Espera-se, desse modo, corroborar correntes de estudos atuais (Duarte et al., 2010; 2013; Savickas, 2009; 2012; 2013, dentre outros) que vêm defendendo a importância de análises contextualizadas e individualizadas acerca dos processos de escolha profissional e construção de carreira, descrevendo como essa construção se dá efetivamente, a partir da análise das trajetórias dos sujeitos deste estudo.

\section{Método}

Com base no objetivo proposto, tomou-se como sujeitos de pesquisa egressos de um programa de Orientação Profissional de uma universidade pública federal. Este programa tem como objetivo atuar como um projeto de extensão à comunidade, atendendo especialmente a população de baixa renda. O trabalho é desenvolvido por estudantes de Psicologia da instituição.

O programa busca facilitar as escolhas profissionais, fomentando a reflexão sobre esse tema e o autoconhecimento. Caracteriza-se pelo atendimento individual baseado na perspectiva clínica. Nessa modalidade busca-se compreender a personalidade do indivíduo e suas potencialidades, bem como desenvolver uma análise aprofundada dos sentimentos envolvidos na escolha, junto a um trabalho em prol da construção do projeto de vida (Costa, 2007). O processo dura em média 12 (doze) sessões de 50 (cinquenta) minutos, sendo dois atendimentos semanais.

\section{Produção de informação}

A produção da informação foi conduzida pela primeira autora, que no momento cursava mestrado em Psicologia, sendo este trabalho fruto de sua dissertação. Todas as etapas foram orientadas pela segunda autora. Ambas as pesquisadoras possuíam experiência prévia na realização de pesquisas qualitativas e na condução de entrevistas abertas.

Foram realizadas três etapas de investigação para a construção de dados. A primeira etapa foi de análise documental dos relatórios resultantes dos atendimentos de Orientação Profissional; a segunda foi a realização de entrevistas abertas, e a terceira, a construção de um genoprofissiograma.

A análise documental foi realizada com o objetivo de identificar possíveis sujeitos de pesquisa. Foram analisados todos os documentos resultantes dos atendimentos de Orientação Profissional realizados na clínica-escola entre os anos de 2004 a 2007, totalizando 92 (noventa e dois) documentos. O período definido para análise (cerca de 10 anos desde a participação) foi estabelecido visando possibilitar o encontro de diferentes trajetórias, sendo distante o suficiente para contemplar um percurso de formação universitária e inserção no mercado de trabalho. Já a extensão do período analisado (quatro anos) objetivou ser factível para a conclusão do estudo no período de dois anos.

A análise inicial dos relatórios de atendimento permitiu a seleção dos usuários do serviço, que foram identificados quanto à possibilidade participar da segunda etapa pelos critérios: (a) conter dados sobre sua localização e (b) relatório contendo informações referentes à identificação das dúvidas iniciais, descrição do andamento da orientação e delineamento de profissões de preferência do participante ao final do programa. Assim, foram identificados 25 (vinte e cinco) possíveis sujeitos para o estudo. Esses relatórios foram novamente analisados visando à compreensão do processo, identificação das profissões aparentes, fatores ponderados na escolha, elementos que indicassem a construção de um projeto de vida e a escolha ao final do programa. Buscou-se também estar atento a informações relevantes que pudessem surgir e que não estivessem contempladas nos parâmetros acima citados, pois, como indica González Rey (2002), os elementos de relevância podem variar no contato com o material, sendo que informações que não tenham sido consideradas pelo pesquisador, podem surgir como aspectos importantes no curso da pesquisa.

Após tentativas de localização dos sujeitos selecionados na primeira etapa e convites de participação, obteve-se o número de cinco participantes, que concordaram voluntariamente em oferecer seu relato ${ }^{2}$. O encontro entre as participantes e a entrevistadora deu-se individualmente, sendo realizados em horários e locais definidos pelas participantes, como no Setor de Psicologia Aplicada da universidade e residências das mesmas. Os objetivos da pesquisa foram detalhados e foi assinado o Termo de Consentimento Livre e Esclarecido. Durante as entrevistas

2 Observa-se que apenas mulheres se dispuseram a participar do estudo. 
estiveram presentes somente as participantes e a entrevistadora, exceto um dos casos, que contou com a participação da mãe de uma das entrevistadas, a convite da mesma.

Procedeu-se com entrevista aberta, cujo indutor foi o pedido de que o sujeito narrasse sua trajetória desde o contato com o programa até a atualidade. Outras perguntas foram inseridas de acordo com a necessidade e andamento da narrativa.

Esse tipo de indutor coloca o outro diante da necessidade de construir sua experiência em uma área de sua vida, bem como de representar um momento de sua vida em que convergem processos simbólicos e emoções significativos para o sujeito; é o sujeito quem se situa no lugar de onde nos falará (González Rey, 2010, p. 46).

As entrevistas tiveram duração média de 55 minutos e foram gravadas com a autorização das participantes e transcritas na íntegra para permitir análise detalhada das informações. Logo após cada entrevista foi produzido o genoprofissiograma. Segundo Soares-Lucchiari (1997, p. 141), o genoprofissiograma é a produção da árvore genealógica da família visando contemplar as trajetórias profissionais de suas três últimas gerações. Como essa técnica é acompanhada de narrativas, também foi utilizada a gravação em áudio. O genoprofissiograma foi utilizado como instrumento de apoio para a obtenção de informações a respeito das influências familiares, conhecer as condições socioeconômicas do grupo familiar, bem como favorecer a identificação de possíveis determinantes sociais incidentes nas trajetórias. Esse instrumento foi utilizado objetivando estimular e facilitar a expressão do sujeito, de modo que, como defende González Rey (2010, p. 43), "o instrumento privilegiará a expressão do outro como processo, estimulando a produção de tecidos de informação, e não de respostas pontuais". As transcrições foram enviadas para as participantes para que pudessem modificar ou acrescentar o que julgassem necessário, objetivando assim, validar as informações obtidas.

Quanto às questões éticas, os direitos dos participantes foram firmados e garantidos pelo Termo de Consentimento Livre e Esclarecido (TCLE), avaliado e aprovado pela Comissão de Ética em Pesquisa Envolvendo Seres Humanos da instituição de origem (Memorando $n^{\circ}$ 020/2014). Somente as pessoas que concordaram com os aspectos nele contidos compuseram o grupo de sujeitos de pesquisa.

\section{Identificação das participantes e escolhas feitas na Orientação Profissional}

As participantes serão denominadas Renata, Andréia, Luíza, Maria Isabel e Vitória. A escolha pelos nomes foi feita pelas próprias participantes.
Renata participou da Orientação Profissional aos 19 anos, no ano de 2004. Iniciou o processo com o desejo de cursar Administração. No processo de Orientação Profissional confirmou a opção pelo curso.

Andréia realizou Orientação Profissional em 2005, aos 17 anos. Anteriormente havia pensado em cursar Pedagogia, por influência da família e amigos devido a uma experiência de trabalho (Menor Aprendiz) com crianças em uma escola. Porém, antes mesmo de iniciar a Orientação Profissional, havia concluído que não era o que queria para si. Durante todo o processo esteve indecisa e, embora ao final tenha optado pelo curso Técnico em Enfermagem, decidiu que não faria o exame de seleção naquele ano, devido a problemas emocionais e familiares.

Luíza participou da Orientação Profissional no ano de 2006, aos 18 anos. Na época estava dividida entre Administração de Empresas e Comunicação Social. Escolheu o curso de Administração.

Maria Isabel também realizou a Orientação Profissional no ano de 2006, aos 18 anos. Iniciou o processo pensando nas profissões de Psicologia, Pedagogia e Fisioterapia. Durante o programa eliminou o curso de Fisioterapia e ampliou suas opções, passando a considerar os cursos de Turismo, Fonoaudiologia, Engenharia Ambiental e Gastronomia. Ao final, não escolheu. Porém, definiu que faria um curso oferecido na universidade pública de sua cidade, retornando à Pedagogia e Psicologia.

Vitória realizou a Orientação Profissional aos 17 anos, em 2007. Já havia sido aprovada no vestibular para o curso de Direito em uma faculdade privada e buscou atendimento para confirmar a escolha. Apesar de apresentar outros interesses profissionais, permaneceu com a escolha ao final do processo.

Assim, o grupo pesquisado é constituído por duas participantes que estavam em dúvida entre algumas ocupações e decidiram ao final da Orientação Profissional, duas participantes que queriam apenas confirmar a escolha, tendo essa sido confirmada, e uma participante que não escolheu uma profissão ao final do programa, mas definiu que, devido à questão socioeconômica, teria que optar por um curso que fosse ofertado na universidade gratuita da cidade.

\section{Análise das informações}

Os resultados foram analisados com base na Epistemologia Qualitativa de González Rey (2010; 2002). Nessa modalidade de pesquisa, a produção de conhecimento é um processo construtivo-interpretativo, que se baseia na integração entre as informações obtidas através dos participantes, o conhecimento já existente sobre o tema e as racionalizações do pesquisador. Essa abordagem enfatiza a importância da interação entre pesquisador e pesquisado, assinalando que toda informação obtida 
nesse contato é relevante, mesmo que surja por meio de imprevistos ou em momentos de informalidade. Outra importante característica da Epistemologia Qualitativa é a defesa da singularidade como condição legítima para a produção do conhecimento, bastando que a informação seja apresentada por um sujeito para que se constitua em informação válida para a produção do conhecimento. Nesse sentido, o que importa é a qualidade da informação e não a quantidade de vezes em que ela aparece (González Rey, 2010).

A análise, como proposta pelo autor, deu-se pela construção de indicadores, que são resultado da integração dos dados empíricos às reflexões dos pesquisadores e às construções teóricas pré-existentes. A partir dos indicadores, deu-se o desenvolvimento das categorias, que representam as zonas de sentido do objeto estudado e serão tratadas na seção Resultados e Discussão.

\section{Resultados e Discussão}

As trajetórias construídas pelas participantes serão analisadas por meio de 12 (doze) zonas de sentido, sendo: Influência dos pares, Influência da família, Família como base para o desenvolvimento profissional, Condições socioeconômicas deficitárias, Comprometimento da saúde, Estratégias utilizadas no enfrentamento de determinantes, Oportunidades, Valorização da formação, Busca pelo primeiro emprego, Das belezas e durezas do trabalho, Planos para o futuro e "Deixo a vida me levar", detalhadas na sequência. As zonas de sentido foram identificadas no contato com o material e então analisadas a partir do referencial teórico, não tendo sido previamente estabelecidas.

\section{Influências sobre o percurso}

Nas trajetórias analisadas, as influências foram identificadas em duas diferentes zonas de sentido: Influência dos Pares e Influência da família. As influências dos pares estiveram presentes, em alguns casos de forma definidora. Apareceram de forma explícita, como no fragmento que segue: "quase que eu fiz Letras, mas aí me tiraram de ideia, falaram que o campo era ruim. (...) Aí falavam assim: ah, Administração tem um leque de oportunidades", disse Luíza, que cursou Administração e atua na área. Também foram encontradas formas indiretas, sem a intenção de influenciar, como as ocasionadas pelo contato com profissionais e com o ambiente de trabalho. A influência do ambiente de trabalho foi preponderante na trajetória de Andréia, que, ao iniciar em um emprego no setor financeiro de uma concessionária de automóveis, identificou-se com a área e atualmente cursa Economia (na Orientação havia escolhido Técnico em Enfermagem).
O nível de influência dos pares na escolha ainda é controverso, havendo estudos que demonstram esse fator (Bohoslavsky, 1987; Santos, 2005), enquanto outros defendem esse tipo de influência como pouco percebida pelos sujeitos que escolhem (Pereira \& Garcia, 2007). Neste estudo, constatou-se que o grupo de pares surgiu como fonte relevante de influência. Como indica Savickas (2012), a identidade profissional é permeada pela relação com o grupo social de identificação, de modo que o sujeito passa a construir objetivos e valores condizentes com os daquela comunidade.

A família também surgiu como fonte relevante de influência. Identificadas na zona de sentido Influência da Família também foram encontradas influências diretas e indiretas. Um exemplo de influência familiar direta é visto na trajetória de Vitória, que cresceu ouvindo de seus familiares qual carreira deveria seguir:

minha mãe que desde pequena falava: ah, você vai fazer é direito! E eu falo: quê isso mãe, vou não. Ah, você vai! Não, vou não! Ai meu tio falava: você vai ser juiza! (...) Ai eu comecei a pensar, quem sabe o direito mesmo?

Vitória estudou Direito, atualmente advoga e planeja prestar concurso público na área jurídica. Como mostra Almeida e Pinho (2008), um filho sempre nasce envolto em expectativas de seus pais e mesmo de outros familiares e a escolha profissional não está imune a elas, como pode ser percebido nessa trajetória.

Influências indiretas também foram percebidas, em especial a influência por identificação. Na família de Maria Isabel, aparece a figura da avó paterna, que ocupa posição central no seio familiar, sendo influente para toda a família. Descrita como professora em tempo integral, por suas ações inspiradoras e sua lição de vida, sua influência pôde ser percebida na escolha profissional dos três netos. Maria Isabel, assim como seus irmãos, escolheu ser professora, cursou Pedagogia e dá aulas na educação infantil. E a influência da avó não é refletida apenas nessa área, é desse convívio que surge o interesse pela Gastronomia, área que vem ganhando cada vez mais espaço em sua vida.

A família também pode exercer influência indireta ao representar um ambiente profícuo para o desenvolvimento de certas habilidades e papéis mais tarde assumidos como escolhas profissionais (Andrade, 1997). Assim ocorreu com a Renata, que assumiu o papel de cuidadora em sua família e, mais tarde, abandonou o projeto de cursar Administração e enveredou-se pela área da saúde. Não podemos afirmar se, neste caso, a influência deu-se unicamente pelo desenvolvimento do papel de cuidador ou pelo fator reparatório que a escolha profissional pode assumir. Todavia é inegável que a experiência vivida teve um papel relevante em seu percurso, fomentando a construção de um novo sentido para os momentos de sofrimento com 
os entes queridos, transformando-os em uma identificação positiva com o ambiente hospitalar e desejo de ajudar outras pessoas em situação de enfermidade. Como indica Savickas (2012, p. 14, tradução nossa), “os indivíduos começam a formar identidades psicossociais associando o eu psicológico a papéis sociais e representações culturais. No momento oportuno, os indivíduos agrupam e articulam uma narrativa de identidade compreensível”, tal como pode ser visto no caso de Renata, em que o papel social de cuidadora exercido por um longo tempo em sua vida culminou em uma identificação profissional com a área da saúde.

Os dramas familiares também surgiram como fator de influência nas trajetórias. É o caso de Andréia, que optou por não fazer vestibular quando se formou, devido a questões emocionais geradas por conflitos familiares: "eu estava muito indecisa, e foi num período, ele [o orientador], falou assim que poderia ser por algo que eu estava passando, e foi num período que os meus pais estavam se separando". Afirma Andréia que, à época da Orientação Profissional, escolheu o curso Técnico de Enfermagem, mas decidiu que não faria o processo seletivo naquele ano devido a questões de cunho familiar e emocional.

A família também se destacou pela zona de sentido Familia como base para o desenvolvimento profissional. Todas as participantes enfatizaram a importância do grupo familiar no alcance dos objetivos profissionais. Um exemplo do suporte familiar pode ser visto na história de Maria Isabel, cujos pais se mudaram com a família para uma cidade universitária para que os filhos tivessem acesso aos estudos:

Ele [pai] ficou assim: eu não tenho idade mais pra procurar serviço não, mas ah, eu vou lá (...), quem sabe se eu arrumo um serviço (...). Num dia bem chuvoso, deixou o carro em casa $e$ veio de ônibus. Chegou aqui, andou, andou, deixou uns currículos. Voltou de tarde. (...). [No dia seguinte] alguém ligou lá na minha casa procurando pelo João, falou assim: (...) ontem ele deixou currículo na minha loja e a senhora fala com ele que se ele quiser vir aqui pra gente conhecer (...). Ah, no outro dia ele veio e já na segunda ele veio pra ficar. (...) E eu acho que isso ai decidiu no curso delas duas [Maria Isabel e sua irmã]. (Fala da mãe de Maria Isabel, em participação na entrevista).

O apoio familiar se mostrou fundamental para os percursos profissionais analisados. A relevância da família nas escolhas durante o período acadêmico e nas trajetórias profissionais são também identificadas respectivamente por Santos (2005), Fiorini, Moré e Bardagi (2017) e Mota-Santos e Carvalho Neto (2017).

\section{Os obstáculos encontrados no percurso}

Muitos elementos contextuais podem interferir no percurso profissional. Nas trajetórias analisadas esses elementos foram divididos em duas zonas de sentido: Condições socioeconômicas deficitárias e Comprometimento da saúde. Na zona de sentido Condições socioeconômicas deficitárias observou-se como indicadores a condição educacional deficitária, a necessidade de trabalhar enquanto estudava e a localização geográfica associada à baixa condição financeira. Esses indicadores assumiram a seguinte dinâmica: acesso a um ensino precário e consequente reprovação no vestibular, que por sua vez aponta para o número insuficiente de vagas no ensino superior gratuito; condição socioeconômica baixa, que exigiu que algumas participantes trabalhassem e, portanto, determinou os cursos universitários e técnicos possíveis de serem frequentados por elas; localização geográfica, também associada à classe econômica, já que as participantes cujas famílias não tinham condições de as manterem em outra cidade tiveram que escolher dentre os cursos existentes em suas cidades.

A zona de sentido Comprometimento da saúde apresenta a doença como um forte determinante, especialmente quando relacionada à condição econômica desfavorável. Como indicam Duarte et al. (2010), problemas de saúde podem afetar a decisão sobre o que fazer na vida profissional. Este foi o caso de Andréia que, pouco antes de iniciar seu estágio, último requisito para a conquista do diploma de curso Técnico em Mineração, quebrou o braço e teve complicações, necessitando ficar muito tempo afastada do curso e do emprego. Quando conseguiu se recuperar, viu-se sem condições de continuar sacrificando a mãe, que mantinha as despesas da casa. Assim, abriu mão do diploma do curso e foi em busca de um novo trabalho.

Outro percurso afetado pela doença foi o de Renata. Aos 19 anos estava cursando o $3^{\circ}$ ano do ensino médio quando teve uma paralisia facial. Como a família não tinha condições de arcar com as despesas do tratamento, seu pai, que sofria com uma enfermidade na coluna, precisou abandonar o tratamento para, juntamente com o plano de saúde da empresa, conseguir pagar as despesas médicas da filha. Após este período Renata ressignificou sua existência. Desistiu de fazer Administração, e construiu um novo percurso, marcado pela resignação. Após o episódio da doença e seu tratamento, Renata precisou trabalhar para se sustentar e ajudar a família, iniciando seu percurso profissional como faxineira diarista, seguido de faxineira contratada e posteriormente promovida a atendente de farmácia. Atualmente segue trabalhando na mesma farmácia e faz curso Técnico em Análises Clínicas.

A condição socioeconômica já havia sido apontada por diversos autores (Bastos, 2005; Dias \& Soares, 2012; Ferretti, 1988), como fator relevante para a concretização das escolhas. Em seu estudo com ex-estudantes de 
escola pública, Bastos (2005) verificou que a necessidade de lutar pela sobrevivência foi determinante em várias ações dos sujeitos, limitando drasticamente a liberdade de escolha dos participantes. Ferretti (1988) afirma que, para indivíduos das classes mais pobres, poucas vezes há a possibilidade de realização de uma escolha de fato, sendo quase sempre necessário se adaptar às oportunidades que surjam. Nesse estudo, a maioria das participantes sofreu de algum modo com este fator limitador. No entanto, algumas estratégias foram eficazes para driblar parte dos efeitos desses determinantes.

\section{As estratégias utilizadas no enfrentamento de determinantes}

Na zona de sentido Estratégias utilizadas no enfrentamento de determinantes destacam-se os indicadores: realização de cursinho pré-vestibular; "madrugar" para conseguir uma vaga em curso gratuito; escolher um curso com menor nota de corte no vestibular para posterior transferência; fazer o ENEM todos os anos, para estar preparado caso surja uma nova oportunidade educacional; fazer um segundo curso como complemento. A fé religiosa também surgiu como estratégia, utilizada quando nenhuma outra foi eficaz. É possível ver como ela se apresenta no trecho que segue: "passei como sétima excedente, eu falei, pedi a Deus, comecei a rezar, [para] pelo amor de Deus essas seis desistir, porque eu queria fazer aquele curso" (Renata).

A partir do exposto podemos afirmar que em vários momentos as participantes utilizaram ações intencionais, direcionadas a um alvo bem delimitado em suas trajetórias. Assim, quando decidiram fazer um curso para mudar de vida, quando optaram por madrugar para garantir uma vaga em curso gratuito, ou sacrificaram a pouca condição financeira na realização de um cursinho pré-vestibular, estavam intervindo conscientemente na própria realidade, objetivando modificar o próprio percurso.

Ao identificar-se os obstáculos encontrados no caminho e as estratégias utilizadas pelos sujeitos no enfretamento desses, podemos identificar o movimento de adaptabilidade de carreira proposto por Savickas (2013). As quatro dimensões por ele identificadas parecem estar presentes nas trajetórias das participantes: preocupação, controle, curiosidade e confiança (Ambiel, 2014; Duarte, Silva, \& Paixão, 2017; Savickas, 2013), na medida em que elas se preocuparam com seu futuro profissional, se propuseram a assumir o controle da própria vida, foram curiosas em conhecer e testar a si e ao meio e tiveram fé no alcance de resultados positivos.

\section{As oportunidades no caminho}

Outro aspecto proeminente em todas as trajetórias caracterizou-se pela zona de sentido Oportunidades.
Essa se diferencia da estratégia, por se tratar de um evento que ocorre independentemente da ação direta e do planejamento do sujeito. Nas trajetórias investigadas as oportunidades se constituíram em elementos de fundamental importância para o desenvolvimento profissional. Algumas mais marcantes foram: trabalhar em um ambiente estimulante que conduziu o sujeito à escolha de sua profissão; oportunidade de estudos na própria cidade; oportunidade de crescimento profissional dentro da empresa em que trabalhava; oportunidades geradas pela rede de contatos e, finalmente, oportunidades geradas pelas políticas públicas.

A rede de contatos aparece no meio organizacional como um elemento importante na construção da carreira (Lopes \& Cunha, 2011; Minarelli, 2001). Nas trajetórias pesquisadas, essa rede também surge como elemento de relevância para a construção dos percursos profissionais. Maia e Mancebo (2010) encontraram em pesquisa com jovens estagiários que a rede de contatos é um elemento de grande valia para a inserção e permanência desses no mundo do trabalho. Neste estudo, pôde-se identificar que a rede de contatos oportunizou a entrada no mercado de trabalho, sua permanência e até mesmo auxiliou no acesso à capacitação das participantes.

$\mathrm{Na}$ zona de sentido Oportunidades destacou-se ainda a assistência governamental, que demonstra como as políticas públicas têm chegado à população de maior carência e modificado as trajetórias dos sujeitos contemplados. Várias são as ações governamentais citadas, desde o âmbito municipal até o federal. Dentre elas, o Programa Jovem Aprendiz, que tem como exigência que o trabalho de menores de 18 anos seja realizado na modalidade aprendiz, sendo assegurada a formação técnico-profissional e atividades compatíveis com a vida escolar e com a etapa de desenvolvimento em que se encontra o adolescente (Amazarray, Thomé, Souza, Poletto, \& Koller, 2009). Foram citados, ainda, a educação gratuita, seja ela pelo acesso à universidade pública ou ao Programa Universidade Para Todos (Prouni), as bolsas de Iniciação Científica e de Atividade ofertadas pelas universidades, e até mesmo os projetos de Extensão Universitária que, ao adentrar o universo das comunidades, puderam beneficiar algumas das participantes.

\section{Sobre a formação e atuação no mundo do trabalho}

No que tange à formação universitária, identificou-se a zona de sentido Valorização da formação. Essa zona de sentido é marcada pela identificação com a profissão e o desejo de atuar na área escolhida, como pode ser percebido na fala de Maria Isabel que enfatiza: "eu fiquei quatro anos dentro da faculdade, estudei, eu não quero pôr meu diploma na gaveta".

Outra zona de sentido identificada foi a Busca pelo primeiro emprego. Pode-se elencar alguns indicadores que 
apontam dificuldades nesse momento, como a exigência de experiência e a necessidade de se submeter a "bicos" até encontrar um trabalho fixo. Por outro lado, um facilitador foi identificado pelas participantes: o estágio. Para duas delas a oportunidade do primeiro emprego surgiu dos estágios realizados no período da faculdade. Esse elemento também foi identificado por Maia e Mancebo (2010), que relatam em seu estudo que o estágio surgiu como uma importante ferramenta para o aprendizado, seja de maneira direta, pela aprendizagem das tarefas associadas à ocupação, ou indireta, auxiliando na adequação do perfil profissional para aquele desejado pelo mercado de trabalho.

Quanto à atuação profissional, pode-se perceber que, para as participantes, o trabalho assume um caráter dual, no qual ora encontra-se satisfação naquilo que é vivido, ora apresenta-se a frustração. Esses aspectos dão origem à zona de sentido Das belezas e durezas do trabalho. Essa condição dual do trabalho já havia sido relatada por Blanch Ribas (2003), que defende que o trabalho pode ser entendido tanto de um polo positivo, em que é visto como "fonte de satisfação e de autorrealização" (p. 47), quanto pelo polo negativo, em que assume o lugar de sacrifício. Compõem essa zona de sentido o choque entre teoria e prática ao concluir que a faculdade não prepara suficientemente e não representa de forma verossímil a atuação profissional; a desvalorização profissional e a desvalorização salarial, bem como a dificuldade de encontrar emprego. A sobrecarga de trabalho foi outro aspecto apontado pelas entrevistadas. Apesar dessas críticas, as participantes ressaltaram em um polo positivo o fato de se identificarem com suas profissões e estarem fazendo o que gostam. Como se pode ver na fala de Maria Isabel, descrita a seguir.

\section{É dificil? É. Muito difícil, mas, se a pessoa gostar, se a pessoa tiver o prazer em fazer aquilo ali, pode ter salário baixo, pode ser desvalorizado (...), se você gosta, se você faz bem feito, (...) também assim, sem conformar também, né, por- que não é: ah, eu amo o que eu faço, então se eu tô ganhando pouco não tem problema. Aí tam- bém não, né, acho que a gente tem que lutar pela nossa profissão.}

Pode-se perceber que, como indicado por Rodrigues, Álvaro e Rondina (2006), as participantes, assim como a grande maioria dos trabalhadores, estão expostas a condições de pressão e conflitos em seu cotidiano, tendo, muitas vezes, suas expectativas frustradas em relação ao trabalho. Por outro lado, vê-se que o trabalho também é percebido como fonte de satisfação, possuindo características positivas quando se faz aquilo com o que se identifica.

\section{A caminhada continua: aspirações profissionais}

Duas zonas de sentido foram identificadas quanto à prospecção de futuro das participantes: Planos para $o$ futuro versus “Deixo a vida me levar". É possível perceber que existem duas tendências quando se trata da continuidade da trajetória profissional das pesquisadas. A primeira tendência, de planejamento do futuro, mostra uma postura esperançosa e repleta de projetos de médio e longo prazo. A outra, apresentada pela zona de sentido "Deixo a vida me levar" mostra que para aqueles cujos planos na maioria das vezes não se concretizaram, fez-se a opção por deixar a vida seguir sem muitos projetos. Esta zona de sentido pode ser ilustrada pela fala de Renata:

Eu deixo a vida me levar, não tem essa de que, você vai ficar escolhendo muito pra que? Tudo que eu escolhi, é o que eu te falei, tudo que eu escolhi deu errado, tudo, então assim, estou fazendo, se der certo...

Como já indicava Ferretti (1988), para os indivíduos com poucas condições socioeconômicas, muitas vezes o que resta é adaptar seus projetos de vida, realizando escolhas menos ambiciosas, para, assim, transitarem por caminhos possíveis.

Como demonstrado, diversos elementos do contexto podem afetar escolhas em diferentes momentos das trajetórias, sendo que, neste estudo, estiveram, em sua maioria, relacionados a condições socioeconômicas. O comprometimento da saúde também surgiu como elemento fortemente capaz de alteração de percursos profissionais. As influências percebidas nas trajetórias estiveram relacionadas aos pares e à família. A família, representando mais do que fator de influência, surgiu como base para a construção das carreiras. Uma série de estratégias para modificação da realidade foi identificada, sendo diferenciadas as estratégias (fruto de agência dos sujeitos) das oportunidades surgidas. Cabe enfatizar os efeitos da relação entre contexto e poder de ação nas perspectivas de futuro, onde se pode verificar que sujeitos que conseguiram através de estratégias e oportunidades modificar suas condições e alcançar objetivos, tornaram-se pessoas mais esperançosas e planejadoras, enquanto aqueles que não conseguiram eliminar as barreiras tornaram-se resignadas e evitativas quanto a projeções de futuro.

\section{Considerações finais}

Este estudo buscou investigar as trajetórias profissionais de egressos de um programa de Orientação Profissional visando compreender como os participantes construíram suas trajetórias desde sua participação no programa. Para tal, identificou-se e analisou-se como se 
articularam diversos elementos em seus percursos. Foram eles: as influências dos pares e da família, os obstáculos, as estratégias, as oportunidades, a formação e atuação no mundo trabalho. Também foi identificado como esses elementos afetaram o planejamento de futuro.

Ao investigar trajetórias profissionais desde a participação em um programa de Orientação Profissional até cerca de 10 anos de construção de carreiras pôde-se, tal como proposto neste estudo, ilustrar a relação dialética que se estabelece no processo de construção de uma carreira, no qual elementos do contexto estão sempre presentes interagindo com os processos de escolha dos sujeitos. Estes são chamados a responderem seja com estratégias de modificação da realidade, seja com a aceitação dela, optando por novos percursos. Ao identificar a interrelação entre essas dimensões na construção de trajetórias profissionais pelas participantes, acredita-se ter ilustrado o fenômeno da adaptabilidade de carreira (Ambiel, 2014; Duarte et al, 2017; Fiorini et al., 2016; Savickas, 2013), essencial na construção do percurso profissional dos profissionais da atualidade.

A necessidade de que "a questão da interação entre o poder de ação pessoal e a estrutura social sejam transformadas em questões científicas" é apontada por Duarte et al. (2010, p. 395). Essa foi a intenção deste estudo e espera-se ter contribuído com a área. Espera-se ter demonstrado também a importância de que o orientador aborde e auxilie seu orientando a refletir sobre o contexto envolvido em suas escolhas e na construção de sua carreira, pois tomando consciência desses elementos

o participante poderá aumentar suas chances de desenvolver estratégias que favoreçam a concretização de seu projeto profissional.

Quanto às limitações deste trabalho, apontamos a ausência de sujeitos do sexo masculino, devido à recusa destes em contribuir com o estudo, o que pode ter reduzido o alcance dos resultados. Assim, para uma futura agenda de pesquisa, sugerimos um estudo que contemple as trajetórias profissionais de pessoas desse sexo.

\section{Referências}

Almeida, M. E. G. G., \& Pinho, L. V. (2008). Adolescência, família e escolhas: implicações na orientação profissional. Psicologia Clínica, 20(2), 173-184. doi:10.1590/S0103-56652008000200013.

Ambiel, R. A. M. (2014). Adaptabilidade de carreira: uma abordagem histórica de conceitos, modelos e teorias. Revista Brasileira de Orientação Profissional, 15(1), 15-24.

Arthur, M. B. (1994). The boundaryless career: a new perspective for organization alinquiry. Journal of Organizational Behavior, 15(4), 295-306.

Arthur, M. B., \& Rousseau, D. M. (1996). The boundaryless career: a new employment principle for a new organizational era. New York, NY: Oxford University Press.

Amazarray, M. R., Thomé, L. D., Souza, A. D., Poletto, M., \& Koller, S. H. (2009). Aprendiz versus trabalhador: adolescentes em processo de aprendizagem. Psicologia: Teoria e Pesquisa, 25(3), 329-338. doi:10.1590/ S0102-37722011000100004.

Andrade, T. D. A. (1997). A família e a estruturação ocupacional do indivíduo. In Levenfus, R. S. (Org.), Psicodinâmica da Escolha Profissional (pp. 123-135). Porto Alegre, RS: Artes Médicas.

Bastos, J. C. (2005). Efetivação de escolhas profissionais de jovens oriundos do ensino público: um olhar sobre suas trajetórias. Revista Brasileira de Orientação Profissional, 6(2), 31-43.

Bendassolli, P. F. (2009). Recomposição da relação sujeito-trabalho nos modelos emergentes de carreira. Revista de Administração de Empresas, 49(4), 387-400. doi:10.1590/S0034-75902009000400003.

Blanch Ribas, J. M. (2003). Trabajar en la modernidad industrial. In J. M. Blanch Ribas, J. M., Tomás, M. J. E., Durán, C. G., \& Artiles, A. M. (Eds.), Teoría de las relaciones laborales: Fundamentos (pp. 19-148). Barcelona, ES: Editorial UOC, 19-147.

Bohoslavsky, R. (1987). Orientação vocacional: a estratégia clínica. $7^{\mathrm{a}}$. Edição. São Paulo, SP: Martins Fontes.

Certeau, M. (1994). A invenção do cotidiano: artes de fazer (vol.1). Petrópolis, RJ: Vozes. 
Chanlat, J. F. (1995). Quais carreiras e para qual sociedade?(I). Revista de Administração de Empresas, 35(6), 67-75.

Costa, N. G. B. (2007). Adolescência e escolha profissional: a escuta de um impasse. Dissertação de mestrado não publicada, Universidade Federal do Pará, Belém, Pará.

Dias, M. S. L., \& Soares, D. H. P. (2012). A escolha profissional no direcionamento da carreira dos universitários. Psicologia Ciência e Profissão, 32(2), 272-283. doi:10.1590/S1414-98932012000200002

Duarte, M. E. (2013). A vida da orientação na vida do século XXI: constrangimentos e desafios. Revista Brasileira de Orientação Profissional, 14(2), 155-164.

Duarte, M. E., Lassance, M. C., Savickas, M. L., Nota, L., Rossier, J., Dauwalder, J., ... Vianen, A. E. M. (2010). A construção da vida: um novo paradigma para entender a carreira no século XXI. Interamerican Journal of Psychology, 44(2), 392-406.

Duarte, M. E., Silva, J. T., \& Paixão, M. P. (2017). Career adaptability, employability, and career resilience in managing transitions. In K. Maree (Ed.), Psychology of career adaptability, employability and resilience.( 1a ed., pp. 241-261). Cham, SWZ: Springer.

Ferretti, C. J. (1988). Uma nova proposta de Orientação Profissional. São Paulo, SP: Cortez.

Fiorini, M. C., Bardagi, M. P., \& Silva, N. (2016). Adaptabilidade de carreira: Paradigmas do conceito no mundo do trabalho contemporâneo. Revista Psicologia: Organizações e Trabalho, 16(3), 236-247. doi:10.17652/rpot/2016.3.676

Fiorini, M. C., Moré, C. L. O. O., \& Bardagi, M. P. (2017). Família e desenvolvimento de carreira de jovens adultos no contexto brasileiro: revisão integrativa. Revista Brasileira de Orientação Profissional, 18(1), 43-55. doi:10.26707/1984-7270/2017v18n1p43.

González Rey, F. L. (2002). Pesquisa qualitativa em Psicologia: caminhos e desafios. São Paulo, SP: Pioneira Thomson Learning.

González Rey, F. (2010). Pesquisa qualitativa e subjetividade: os processos de construção da informação. São Paulo, SP: Cengage Learning.

Hall, D. T. (1976). Careers in organizations. California: Goodyear Pub, Pacific Palisades.

Hall, D. T. (2004) The protean career: a quarter-century journey. Journal of Vocational Behavior, 65, 1-13.

Lopes, M. P., \& Cunha, M. P. (2011). O mundo é pequeno. O que podemos aprender sobre o networking e as redes sociais. Lisboa, PT: Actual Editora.

Maia, A. A. R. M., \& Mancebo, D. (2010). Juventude, trabalho e projetos de vida: ninguém pode ficar parado. Psicologia: ciência e profissão, 30(2), 376-389.

Melo-Silva, L. L., Lassance, M. C. P., \& Soares, D. H. P. (2004). A Orientação Profissional no contexto da Educação e Trabalho. Revista Brasileira de Orientação Profissional, 5(2), 31-52.

Minarelli, J. A. (2001). Networking: como utilizar a rede de relacionamentos na sua vida e na sua carreira. $6^{\mathrm{a}}$ Edição. São Paulo, SP: Editora Gente.

Mota-Santos, C. M., \& Carvalho Neto, A. M. (2017). O papel da família na trajetória profissional de mulheres executivas e empreendedoras. Revista Alcance, 24(1), 36-49. doi:10.14210/alcance.v24n1.p036-049

Pereira, F. N., \& Garcia, A. (2007). Amizade e escolha profissional: influência ou cooperação? Revista Brasileira de Orientação Profissional, 8(1), 71-86.

Ribeiro, M. A. (2009). A trajetória da carreira como construção teórico-prática e a proposta dialética da carreira psicossocial. Cadernos de Psicologia Social do Trabalho, 12(2), 203-216. doi:10.11606/issn.1981-0490.v12i2p203-216.

Rodrigues, P. F., Álvaro, A. L. T., \& Rondina, R. (2006). Sofrimento no trabalho na visão de Dejours. Revista Cientifica Eletrônica de Psicologia, 4(7).

Santos, L. M. M. (2005). O papel da família e dos pares na escolha profissional. Psicologia em Estudo, 10(1), 57-66.

Savickas, M. L. (2012). Life Design: a paradigm for career intervention in the 21 st century. Journal of Counseling \& Development, 90, 13-19. 
Savickas, M. L. (2013). The theory and practice of career construction. In S. D. Brown \& R. W. Lent (Eds.), Career development and counselling: putting theory and research to work (2a ed., pp. 147-183). Hoboken: Wiley.

Savickas, M. L., Nota, L., Rossier, J., Dauwalder, J., Duarte, M. E., Guichard, J., Soresi, S., Esbroeck, R. V., \& Vianen A. E. M. van. (2009). Life designing: A paradigm for career construction in the 21 st century. Journal of Vocational Behavior, 1-12.

Soares-Lucchiari, D. H. (1997). Uma abordagem genealógica a partir do Genoprofissiograma e do Teste dos três personagens. In R. S. Levenfus (Org.). Psicodinâmica da escolha profissional (pp. 135-162). Porto Alegre, RS: Artes Médicas.

Recebido: 03/03/17

Aceito: $19 / 10 / 18$

Sobre as autoras:

Tatiane Rose Oliveira de Mendonça é Mestre em Psicologia e Psicóloga pela Universidade Federal de São João del-Rei. Atua como psicóloga clínica e orientadora profissional em consultório particular na cidade de Passos, MG.

E-mail: tatianerose@yahoo.com.br

Larissa Medeiros Marinho dos Santos é Docente do Departamento de Psicologia da Universidade Federal de São João del Rei. Doutora em Psicologia pela Universidade de Brasilía.

E-mail: larissa@ufsj.edu.br 
